\title{
Avaliação da ação antifúngica da ozonioterapia sobre diferentes espécies de Candida para aplicação na cavidade oral - Revisão de Literatura
}

\author{
Antifungal action of ozone therapy assessment against different Candida species for oral cavity \\ application - Literature Review \\ Evaluación de la acción antifúngica de la ozonoterapia contra diferentes especies de Candida para \\ aplicación en la cavidad oral - Revisión de la literatura
}

Recebido: 15/08/2021 | Revisado: 23/08/2021 | Aceito: 28/08/2021 | Publicado: 30/08/2021

\author{
João Vitor Oribka Roque \\ ORCID: https://orcid.org/0000-0002-2233-7865 \\ Universidade Estadual do Oeste do Paraná, Brasil \\ E-mail: jv.oribkaroque@gmail.com \\ Eduardo Alexandre Loth \\ ORCID: https://orcid.org/0000-0002-9496-7268 \\ Universidade Estadual do Oeste do Paraná, Brasil \\ E-mail: eduardo.loth@unioeste.br \\ Lilian Cristiane Baeza \\ ORCID: https://orcid.org/0000-0003-4119-9573 \\ Universidade Estadual do Oeste do Paraná, Brasil \\ E-mail: lilianbaeza@gmail.com
}

\begin{abstract}
Resumo
O gênero Candida é o mais comumente associado ao desenvolvimento de infecção nos tecidos orais, denominada candidose oral. O manejo terapêutico dessa patologia é bem complexo e inclui a utilização de agentes antifúngicos de aplicação tópica ou sistêmica, dependendo da severidade da infecção. Nesse contexto, o objetivo desse estudo foi, por meio de uma revisão de literatura, avaliar a ação antifúngica do ozônio sobre leveduras do gênero Candida, visando aplicação em cavidade oral, pelo fato de o ozônio ser sugerido como terapia alternativa devido a sua ação oxidante. Para tanto, foi realizada busca pelo termo "ozone and Candida" nas bases de dados PubMed, SciELO e BVS por artigos publicados até abril de 2020. Após avaliação foram selecionados 23 artigos que se enquadram nos critérios. Pode-se concluir que o ozônio apresenta uma significante ação antimicrobiana sobre leveduras do gênero Candida. O presente estudo sugere que o seu uso tem a possibilidade de atenuar a resposta curativa dessa infecção, visto que inúmeros estudos tenham relatado melhora nos quadros infecciosos e diminuição de unidades formadoras de colônia. Todavia, novas investigações e comparações de perfil de toxicidade são necessários para estabelecer corretos protocolos de uso clínico.
\end{abstract}

Palavras-chave: Ozônio; Antifúngico; Biofilme.

\begin{abstract}
The Candida genus is the most commonly associated with the development of infection in oral tissues, called oral candidiasis. The therapeutic management of this pathology is quite complex and includes the use of topical or systemic antifungal agents, depending on the severity of the infection. In this context, the aim of this study was, through a literature review, to evaluate the antifungal action of ozone on yeasts of the Candida genus, aiming for application in the oral cavity, as ozone is suggested as an alternative therapy due to its oxidizing action. For this purpose, a search for the term "ozone and Candida" was performed in the PubMed, SciELO and BVS databases for articles published until April 2020. After evaluation, 23 articles that met the criteria were selected. It can be concluded that ozone has a significant antimicrobial action on Candida genus yeasts. The present study suggests that its use has the possibility of attenuating the curative response of this infection, since numerous studies have reported an improvement in infectious conditions and a decrease in colony-forming units. However, further investigations and toxicity profile comparisons are needed to establish correct protocols for clinical use.
\end{abstract}

Keywords: Ozone; Antifungal; Biofilm.

\section{Resumen}

El género Candida es el más comúnmente asociado con el desarrollo de una infección en los tejidos bucales, denominada candidiasis oral. El manejo terapéutico de esta patología es bastante complejo e incluye el uso de agentes antifúngicos tópicos o sistémicos, según la gravedad de la infección. En este contexto, el objetivo de este estudio fue, a través de una revisión de la literatura, evaluar la acción antifúngica del ozono sobre levaduras del género Candida, 
con el objetivo de su aplicación en la cavidad bucal, ya que se sugiere el ozono como terapia alternativa por su acción oxidante. Por lo tanto, se realizó una búsqueda del término "ozono y Candida" en las bases de datos PubMed, SciELO y BVS para los artículos publicados hasta abril de 2020. Luego de la evaluación, se seleccionaron 23 artículos que cumplieron con los criterios. Se puede concluir que el ozono tiene una importante acción antimicrobiana sobre las levaduras del género Candida. El presente estudio sugiere que su uso tiene la posibilidad de atenuar la respuesta curativa de esta infección, ya que numerosos estudios han reportado una mejora en las condiciones infecciosas y una disminución en las unidades formadoras de colonias. Sin embargo, se necesitan más investigaciones y comparaciones de perfiles de toxicidad para establecer protocolos correctos para uso clínico.

Palabras clave: Ozono; Antifúngico; Biopelícula.

\section{Introdução}

A cavidade oral apresenta-se como uma das mais diversas e complexas microbiotas do organismo humano. Estima-se que mais de 500 espécies podem ser identificadas nela, compreendendo fungos, vírus e bactérias, das quais, metade pertencem ao periodonto e as demais ocupam outros microambientes, como língua, mucosas lisas e superfície dental (Paster et al., 2006). Estes microrganismos, são habitualmente comensais, embora, em determinadas circunstâncias possam tornar-se patogênicos. É o que ocorre nas infecções fúngicas orais, provocadas por leveduras do gênero candida (Hahnel et al., 2012). Leveduras do gênero candida são microrganismos comensais humanos que geralmente residem na pele, trato gastrointestinal, sistema geniturinário, orofaringe e trato respiratório superior sem causar danos a indivíduos saudáveis (Yapar, 2014). C. Albicans é um patógeno oportunista, isolado em 30\% a 40\% dos adultos saudáveis (Vanden Abbeele et al., 2008; Abaci et al., 2010).

Esta levedura pode estar presente sem causar nenhum sintoma, no entanto pode causar várias infecções agudas ou crônicas. As candidodes orais podem ser classificadas como primárias e secundárias e apresentar lesões associadas ou não. As candidoses primárias que se manifestam sob a forma aguda são conhecidas por candidose pseudomembranosa e candidose eritematosa e sob a forma crônica, são a candidose em placa e nodular ou hiperplásica. As secundárias são as manifestações orais de candidose mucocutânea sistêmica. Já as lesões associadas à Candida, incluem a estomatite protética, queilite angular e glossite romboide mediana, assim como lesões queratinizadas com superinfecção por Candida como o líquen plano e eritematoso e leucoplasia, ambas consideradas formas primárias (Sherman et al., 2002).

Entre os fatores de virulência, que influenciam esse quadro, pode-se citar a capacidade do fungo em se de aderir a dispositivos médicos ou células hospedeiras, desenvolvimento de biofilme e transição para forma filamentosa (Farah et al., 2010). Além disso, a formação de biofilmes por Candida estão associados à falha do tratamento devido a um alto nível de resistência antifúngica. Permite-se afirmar que a relação parasita-hospedeiro, é dependente de fatores intrínsecos ao hospedeiro, bem como fatores de virulência do fungo, como a capacidade de adesão e de formação de tubos germinativos e a produção de proteases extracelulares. Assim, Candida spp. pode causar infecções por invasão tecidual, indução de estados de hipersensibilidade ou por produção de toxinas (Simões et al., 2018).

Na maioria dos casos, o diagnóstico de Candidose oral é clinico, baseado em sinais e sintomas. Apesar de essas lesões serem normalmente assintomáticas, por vezes os pacientes podem referir sensação de queimadura e dor moderada, ou severa quando associada a ulcerações. Além disso, sintomas como disfagia, disgeusia e halitose podem estar presentes (Fotos \& Hellstein, 1992). Em pacientes saudáveis, a maior parte dos casos de candidose oral são localizados e o tratamento inclui a utilização de agentes antifúngicos, dependendo da severidade da infecção. Podem ser utilizadas, substâncias desinfetantes como clorexidina $0,12 \%$, além de antifúngicos de aplicação tópica como nistatina e miconazol, e em casos mais graves a utilização de fármacos com ação sistêmica como anfotericina B e derivados azólicos (Quindós et al., 2019). No entanto, a busca de novas substâncias, que apresentam menor custo, fácil aplicação e menos toxicidade ao hospedeiro vem crescendo nos últimos anos. $\mathrm{Na}$ área da odontologia, o ozônio vem sendo empregado com essa finalidade, de atuar como um antimicrobiano (Saini, 2011; Tasdemir et al., 2019). 
O ozônio é um gás incolor, apresentando odor característico. Este gás, forma radicais oxidantes na presença de água, que penetram e atacam as membranas celulares, afetando o equilíbrio osmótico, promovendo a oxidação dos aminoácidos e ácidos nucléicos, causando lise celular dependente da extensão das reações (Bocci et al., 2011). Devido a sua alta capacidade oxidante e de formação radicais livres de oxigênio que levam à destruição de microorganismos, o sistema imunológico é ativado para combater patógenos como bactérias, fungos e infecções por vírus (Pivotto et al., 2020). A dose segura de ozônio é variável, dependendo da localização e do objetivo do tratamento. Atualmente, propõe-se uma variação de 10 a $80 \mu \mathrm{g} / \mathrm{ml}$ de ozônio seja benéfica e sem toxicidade. (Smith et al., 2017).

Desta forma, devido à falta de consenso em relação a implementação de protocolos clínicos específicos, o presente estudo teve como objetivo avaliar, por meio de uma revisão de literatura, os protocolos de uso do ozônio sobre Candida spp., bem como a sua eficiência, destacando os principais benefícios e desafios do seu uso clinico.

\section{Metodologia}

Estratégia de pesquisa: Trata-se de uma revisão de literatura estruturada conforme Almeida e colaboradores (2019). Inicialmente, foi definido o termo de pesquisa que incluiu a combinação de duas palavras-chaves específicas, o qual foi "ozone and Candida". Realizou-se então, uma busca computadorizada nos bancos de dados Scientific Electronic Library Online (SciELO), PubMed/MedLine e na Biblioteca Virtual em Saúde (BVS) para artigos publicados até abril de 2020.

Análise de dados: Os resultados encontrados passaram por uma avaliação de título e resumo realizadas por um examinador, sendo incluídos na análise de texto completo apenas os artigos que estivessem devidamente relacionados ao tópico proposto para essa revisão.

Análise de texto completo: Nesta etapa, foi buscado levantar os principais dados acerca do uso do ozônio, como a sua forma de aplicação, tempo, concentração e método para análise de resultados.

\section{Resultados}

Identificação dos estudos: A busca inicial encontrou 123 estudos relacionados ao termo de pesquisa. Após a avaliação de título e resumo, foram excluídos 37 artigos por duplicação e 57 por não atenderem aos critérios de inclusão devido a fuga da temática ou por não terem avaliado apenas do efeito do ozônio, mas, ele associado a outro tipo de antimicrobiano, afetando seu resultado puro. Por fim, após a avaliação completa de texto e exclusão de mais 6 estudos, foram selecionados 23 artigos para essa revisão.

Efeito do uso do ozônio sobre leveduras do gênero Candida.: Dos 23 artigos avaliados, todos foram publicados entre os anos de 1995 a 2020. Analisando a distribuição dos estudos realizados no decorrer desse período, observamos que o ápice de publicações acerca do tema se estabeleceu no ano de 2018. Em relação a metodologia, dos artigos avaliados $78,27 \%$ (18) foram realizados in vitro, enquanto $21,73 \%$ (5) foram realizados in vivo.

Levando-se em consideração que a ozonioterapia está disponível em diferentes tipos de veículos, seja na forma de gás, sob tratamento tópico ou na forma de água ozonizada, para aplicação direta ou parenteral (Pivotto et al., 2020), dos estudos avaliados, 18 utilizaram a ozônio na forma de água e 4 deles na forma de gás. Enquanto 1 avaliou o efeito tanto do gás como da água ozonizada. Sobre as concentrações do ozônio na forma de gás, apenas 2 dos 5 estudos relataram a concentração, que são descritas na Tabela 1. 
Tabela 1 - Concentrações de gás de ozônio utilizadas nos estudos avaliados.

\section{Artigo}

Huth et al., 2008.

Dziugan et al., 2016.

\section{Concentração}

$0,1 \mathrm{~g} \mathrm{O}_{3} / \mathrm{L} \mathrm{O}_{2}$

$1 \mathrm{gm}^{3}$ e $53 \mathrm{gm}^{3}$

Fonte: Autores.

Conforme mostra a Tabela 1, para Dziugan et al. (2016), utilizando a concentração descrita, foi necessário de 8 a 14 minutos de ozonização para iniciar a inativação das cepas microbianas, sendo as células vegetativas mortas após 8 minutos, enquanto esporos e conídios foram inativados após 27 e 30 minutos. O mesmo autor sugere que o curto período de tempo para esterilização é uma vantagem, que fortalece a ozonização ser utilizada em larga escala para desinfecção. Já para Huth et al. (2008), o gás de ozônio em concentrações de $1 \mathrm{gm}^{3}$ por 1 minuto, eliminou quase completamente as cepas testadas, sendo a esterilização completa obtida aumentando-se a concentração e o tempo de contato. Dos estudos que utilizaram o ozônio na forma de água ozonizada e que relataram a concentração, temos essas descritas na Tabela 2.

Tabela 2 - Concentrações de água ozonizada utilizadas nos estudos avaliados, bem como conversão das concentrações em ppm.

\begin{tabular}{|c|c|c|}
\hline Artigo & Concentração & Concentração (ppm) \\
\hline Komanapalli \& Lau, 1998 & $600 \mathrm{ppm}$ & $600 \mathrm{ppm}$ \\
\hline Murakami et. al., 1996 & $10 \mathrm{ppm}$ & $10 \mathrm{ppm}$ \\
\hline Labbe et al., 2001 & $0,2 \mathrm{mg} / \mathrm{L}$ & $0,2 \mathrm{ppm}$ \\
\hline Nagayoshi et al., 2004 & $0,5 \mathrm{mg} / \mathrm{L}$ a $4 \mathrm{mg} / \mathrm{L}$ & 0,5 e 4 ppm \\
\hline Arita et al., 2005 & $0,5 \mathrm{mg} / \mathrm{L}$ a $4 \mathrm{mg} / \mathrm{L}$ & 0,5 e 4 ppm \\
\hline Nagayoshi et al., 2005 & $2 \mathrm{mg} / \mathrm{L}$ & $2 \mathrm{ppm}$ \\
\hline Huth et al., 2008. & $5 \mu \mathrm{g} / \mathrm{mL}$ & $5 \mathrm{ppm}$ \\
\hline Cardoso et al., 2008 & $24 \mathrm{mg} / \mathrm{L}$ & $24 \mathrm{ppm}$ \\
\hline Bezirtzoglou et al., 2008 & $3,5 \mathrm{ppm}$ & $3,5 \mathrm{ppm}$ \\
\hline Kshitish \& Laxman, 2010 & $2 \mathrm{mg} / \mathrm{L} \mathrm{e} 4 \mathrm{mg} / \mathrm{L}$ & 2 e 4 ppm \\
\hline Sadatullah et al., 2012 & 0,08 e $0,1 \mathrm{ppm}$ & 0,08 e $0,1 \mathrm{ppm}$ \\
\hline César et al., 2012 & $10 \mathrm{mg} / \mathrm{L}$ & $10 \mathrm{ppm}$ \\
\hline Eick et al., 2012 & $140 \mathrm{ppm}$ & $140 \mathrm{pmm}$ \\
\hline Borges et al., 2017 & $8 \mu \mathrm{g} / \mathrm{mL}$ & $8 \mathrm{ppm}$ \\
\hline Livingston et al., 2018 & 0,9 e $0,12 \mathrm{ppm}$ & 0,9 e $0,12 \mathrm{ppm}$ \\
\hline Amin, 2018 & $70 \mu \mathrm{g} / \mathrm{cm}^{3}$ & $7000 \mathrm{ppm}$ \\
\hline Savabi et al., 2018 & $200 \mathrm{ppm}$ & $200 \mathrm{ppm}$ \\
\hline Mu et al., 2020 & $25 \mathrm{mg} / \mathrm{L}$ & $25 \mathrm{ppm}$ \\
\hline
\end{tabular}

Fonte: Autores.

De acordo com o apresentado na Tabela 2 observa-se uma considerável divergência quanto as concentrações de água ozonizada. Sadatullah et al. (2012) utilizando 0,08 e 1 ppm obteve resultados, mas a magnitude de esterilização foi questionável. Savabi e colaboradores (2018) utilizaram 200 ppm e mesmo não obtendo esterilização completa, uma redução significativamente estatística no número de colônias após imersão em água ozonizada foi observada, com 5 minutos a taxa de 
redução foi de 20,27\% e com mais 10 minutos uma redução de mais 16,99\%. Enquanto Komanapalli e Lau (1998) com 600 ppm mostrou uma diminuição de 100 vezes quando comparada ao controle de $1 \times 10^{8}$ células $/ \mathrm{mL}$ em 10 minutos e aos 40 minutos a viabilidade dos isolados diminuiu a um fator de $1 \times 10^{4}$ células $/ \mathrm{mL}$.

Ainda em relação ao apresentado na Tabela 2, pode-se observar que Amin (2018) alcançou bons resultados com uma concentração de $70 \mu \mathrm{g} / \mathrm{cm}^{3}$ de água ozonizada, que foi administrada por uma injeção intraperitoneal em ratos induzidos a candidose experimental. Por outro lado, Borges e colaboradores (2017) concluíram com seu estudo que o ozônio isolado a uma concentração de $8 \mu \mathrm{g} / \mathrm{mL}$ não induziu inibição do crescimento visualmente perceptível nas isolados avaliados, embora quando associado a clorexidina obteve um melhor desempenho antimicrobiano.

De dois artigos que utilizaram as mesmas concentrações de água ozonizada - 0,5 mg/L; $2 \mathrm{mg} / \mathrm{L} \mathrm{e} 4 \mathrm{mg} / \mathrm{L}$ - Nagayoshi et al. (2004) relataram que a atividade antimicrobiana do ozônio é depende do tempo de exposição e da concentração, tendo uma redução estabelecida em mais que a metade do controle utilizando $4 \mathrm{mg} / \mathrm{L}$ durante 5 minutos de exposição. Já Arita et al. (2005) apresentaram como resultado que suas placas inoculadas com C. albicans após 1 minuto de imersão em água ozonizada a $4 \mathrm{mg} / \mathrm{L}$ obtiveram uma ligeira diminuição no número de cepas, sendo necessário mais de 30 minutos para que a água ozonizada alcance sua eficácia antimicrobiana completa. Também examinou a atividade citotóxica do fluxo de água ozonizada em C. albicans aderindo às placas de resina. Esse tratamento reduziu significativamente o número de cepas viáveis, mesmo com $0,5 \mathrm{mg} / \mathrm{L}$ de água ozonizada com vazão de $2 \mathrm{~L} / \min$ por 1 minuto. Soma-se a esse dado, o estudo de Livingston e colaboradores (2018) que testaram a eficácia da água ozonizada $(0,9-0,12 \mathrm{ppm})$ em fluxo de 30 segundos a cada 4 horas em uma pia colonizada com Candida auris, sendo as culturas coletadas a cada 4 horas após a desinfecção. Os swabs foram agitados em vórtex em $1 \mathrm{~mL}$ de neutralizador DeyEngley, diluídos em série e semeados em ágar Sabouraud Dextrose. Após o início da desinfecção com água ozonizada, a concentração do patógeno diminuía gradualmente e foi reduzida para níveis indetectáveis no filtro em 2 dias. Os resultados demonstram que a exposição repetida à água ozonizada foi eficaz na redução $C$. auris em pias colonizadas. Os patógenos foram reduzidos a um nível indetectável no filtro, sugerindo que a água ozonizada poderia ser útil para reduzir o risco de contaminação nestas situações. Além disso, segundo o estudo de Eick et al. (2012) Candida albicans sobreviveu em parte após a dupla exposição de 18 seg a água ozonizada na concentração de 140 ppm, tendo taxa de inativação das cepas estabelecida em de $94 \%$.

Atualmente, propõe-se que a variação de 10 a $80 \mu \mathrm{g} / \mathrm{mL}$ de ozônio seja benéfica, levando a efeitos positivos e sem toxicidade, dependendo do tecido, demonstrados in vitro e in vivo em modelos animais. Nos estudos em seres humanos, a faixa de dose segura varia entre 15 e $50 \mu \mathrm{g} / \mathrm{mL}$ e depende do tipo e objetivo do tratamento, bem como do local de aplicação (Pivotto et al., 2020).

Quanto aos métodos para confirmação ou não do efeito que o ozônio tem sobre leveduras do gênero Candida, observou-se que Amin (2018) utilizou coloração histológica de Hematoxilina e Eosina (HE) além de expressão imunohistoquímica para observar reatividade de CD3. A cultura de líquido sinovial foi também utilizada em um estudo in vivo que relatou que o ozônio tenha causado a destruição local de C. parapsilosis, (Mu et al., 2020). O perfil morfológico de C. albicans também foi analisado por microscopia eletrônica de varredura (MEV) anexado às placas de resina antes e após tratamento com ozônio (Muller et al., 2007). Os demais estudos utilizaram a cultura em ágar para contagem de unidades formadoras de colônia (UFC) e os resultados estão descritos na Tabela 3. 
Tabela 3 - Cepa, concentração inicial ([ ] inicial) e concentração final ([ ] final) após tratamento com ozônio dos estudos in vitro que confirmaram o efeito do ozônio sobre leveduras do gênero Candida por meio de contagem de Unidades Formadoras de Colônia.

\begin{tabular}{c|c|c|c}
\hline ARTIGO & CEPA & [ ] inicial & [ ] final \\
\hline Huth et al., 2008 & C. albicans ATCC MYA-273 & $1 \times 10^{8}$ & $1,7 \times 10^{7}$ \\
\hline Livingston et al., 2018 & C. auris MRL 31102 & $1 \times 10^{6}$ & $1,3 \times 10^{4}$ \\
\hline Savabi et al., 2018 & C. albicans PTCC5027 & $1 \times 10^{6}$ & $6,2 \times 10^{5}$ \\
\hline Borges et al., 2017 & C. albicans ATCC10231 & $1 \times 10^{6}$ & $8,3 \times 10^{6}$ \\
\hline Noites et al., 2014 & C. albicans ATCC90028 & $1 \times 10^{8}$ & $1 \times 10^{5}$ \\
\hline Eick et al., 2010. & C. albicans ATCC76615 & $2 \times 10^{8}$ & $2,5 \times 10^{6}$ \\
\hline Nagayoshi et al.,2004. & C. albicans ATCC18804 & $1,5 \times 10^{8}$ & $2,3 \times 10^{6}$ \\
\hline Cardoso et al., 2008. & C. albicans ATCC 29212 & & \\
\hline
\end{tabular}

Fonte: Autores.

Outra característica importante foi o tempo de aplicação, 5 dos estudos avaliados relataram que a ozonioterapia é tempo-dependente, tendo seu início de ação - tempo em que se começa a ser percebida uma diminuição no número de UFC após 5 minutos de aplicação (Restaino, et al., 1995; César et al., 2012; Borges et. al., 2017; Savabi et al., 2018), atingindo seu ápice em 30 minutos (Restaino, et al., 1995). Todavia, um artigo relatou que a água ozonizada manteve sua atividade antimicrobiana até 20 minutos e que essa atividade diminuiu substancialmente após 30 minutos devido à instabilidade do gás $\mathrm{O}_{3}$ (César et al., 2012). Ainda em relação ao tempo de aplicação, um artigo estabeleceu que a eficácia in vitro da água ozonizada se estabeleceu a partir de 10 minutos de contato, além de observar que essa não apresenta efeito residual, pois após um período de tempo os microrganismos restantes se multiplicaram (Cardoso et al., 2008). Soma-se a isso, uma conclusão observada por Shargawi e colaboradores (1999) que relataram que o gás ozônio não exerce efeito sobre $C$. albicans em crescimento.

Por fim, quatro estudos indicaram a necessidade de maiores investigações a respeito do uso do ozônio, devido ao fato da magnitude da inativação antimicrobiana que o ozônio produz ser muito variável (Sadatullah et al., 2012) e de haver pouca informação quanto ao tempo e a concentração para se utilizar o ozônio (Noites et al., 2014). Amin (2018) recomenda que novas investigações e comparações de perfil de toxicidade são necessários para confirmar a terapia com ozônio em infecções humanas, sendo muito importante o fornecimento diretrizes clínicas sobre a aplicação e o manuseio seguro da água ozonizada (Arita et al., 2005).

\section{Discussão}

A crescente incidência de patógenos resistentes a medicamentos, associada um número limitado de opções terapêuticas e a toxicidade dos compostos tradicionais chamaram a atenção para o desenvolvimento de tratamentos alternativos (Tobaldini-Valerio et al., 2016). A ozonioterapia é considerada uma terapia alternativa e tem vários efeitos positivos, mas, dependendo da dose, pode resultar em efeitos nocivos para o indivíduo. Os principais efeitos positivos relatados em humanos são baseados em três funções principais: antimicrobiano, equilíbrio antioxidante/oxidante e efeitos imunomoduladores (Pivotto et al., 2020).

A permeabilidade da membrana é um elemento chave na viabilidade celular e as mudanças nessa permeabilidade envolvem a perda de vários processos vitais. Geralmente é aceito que a oxidação causada pelo ozônio induz a destruição das 
paredes celulares e citoplasmáticas e membranas de microrganismos e que diferenças na sensibilidade da água ozonizada provavelmente são devidas a diferenças na estrutura das paredes celulares dos microrganismos. Após a membrana ser danificada por oxidação, a permeabilidade da membrana aumenta e moléculas de ozônio podem facilmente entrar nas células (Nagayoshi et al., 2004).

Apesar do conhecimento acerca dos benefícios do uso do ozônio, sua aplicação clínica ainda é muito limitada. Nesta revisão, foram avaliados 23 estudos, entre os anos de 1995 a 2020 e durante esse período não se observou uma coerência nos protocolos utilizados, no que diz respeito a concentração, tempo e forma de aplicação.

É importante ressaltar que a ozônio pode ser administrado em fase gasosa ou aquosa, por inúmeras vias. Considerando isso, Sadatullah e colaboradores (2012) por meio de um estudo in vivo afirmaram que o enxágue com água ozonizada é eficaz na redução da carga microbiana da placa e demonstrou ser um agente antimicrobiano poderoso e confiável contra bactérias, fungos, protozoários e vírus, sendo uma adição extremamente útil à escovação e uso do fio dental, pois é bactericida, fácil de preparar e econômico. No entanto, a magnitude de sua inativação sobre microrganismos orais precisa de mais investigação, pois ele não elimina toda a população microbiana da placa dental.

Amin (2018) por meio de um estudo experimental administrou uma injeção intraperitoneal diária de $1 \mathrm{~cm}^{3}$ de uma mistura gasosa de oxigênio e ozônio com concentração de $70 \mu \mathrm{g} / \mathrm{cm}^{3}$ e observou que o ozônio quando administrado terapeuticamente em ratos imunossuprimidos com candidíase oral, reduz efetivamente a lesão da cavidade oral. O exame histológico mostrou infiltração reduzida das camadas superficiais do epitélio lingual com leveduras de Candida quando comparado ao grupo controle. Isso vem de acordo com Tiwari et al. (2017), que relataram que a aplicação de ozônio tem muitos efeitos benéficos nos tecidos orais, compreendendo remissão de várias alterações da mucosa, melhora da cicatrização de feridas e aumento da taxa de rotatividade de células orais.

Safwat e colaboradores (2018) avaliaram o efeito direto do ozônio gaseiforme após a remoção inicial da biomassa cariogênica, juntamente com a camada superficial da dentina infectada. Para o grupo de teste, os valores absolutos e logarítmicos de Candida reduziram significativamente após a aplicação direta de ozônio por 40 segundos, a variação percentual foi de 74,21 $\pm 44,41 \%$ para o grupo de teste. Essa redução significativa pode ter resultado de danos celulares causados pelo ozônio, atribuído a processos simultâneos, como inibição de enzimas intracelulares, depleção de glutationa e danos à membrana, que ocorrem por reação direta entre moléculas alvo e ozônio ou por intermediários oxidantes (Yamayoshi $\&$ Tatsumi, 1993).

Hutt e colaboradores (2006) relatam que o ozônio é um potente agente antisséptico e a forma aquosa mostrou menos citotoxicidade que o ozônio gasoso ou outros antimicrobianos já usados como o digluconato de clorexidina 2\%, o hipoclorito de e o peróxido de hidrogênio, concluindo que o ozônio aquoso atende às características biológicas ideais das células em termos de biocompatibilidade para aplicação oral. Vale ressaltar que o digluconato de clorexidina, substância antimicrobiana já utilizada em clínica odontológica, pode provocar alterações orais como a alteração na coloração dos elementos dentários, perda do paladar, queimaduras no tecido mole, xerostomia, lesões descamativas, ulcerações na mucosa e gosto residual desagradável na boca (Gold, 2008), sendo o ozônio, substância livre de efeitos colaterais, quando utilizando em doses corretas.

Noites e colaboradores (2014) concluíram que a aplicação ozônio gasoso por 24 e 60 segundos não foi suficiente para eliminar C. albicans. Períodos mais altos, como 120 se 180 segundos, embora não completamente eficientes, foram significativamente melhores. A duração da ação pode ser, portanto, uma consideração importante no efeito antimicrobiano do ozônio.

No estudo de César e colaboradores (2012) a água ozonizada foi eficaz na redução dos níveis microbianos de $C$. albicans e essa redução dependia da duração de exposição, considerando que, após 5 minutos de exposição, apenas uma pequena redução não significativa de $0,5 \log$ foi registrada e a esterilização completa foi observada após 30 minutos de 
ozonização porque nenhuma UFC viável foi observada para essas amostras. Segundo os autores, a aplicação de ozônio por curtos períodos teve um efeito bacteriostático, enquanto a ozonização por mais de 30 minutos teve um efeito bactericida. Em contraste a isso, Miguez e colaboradores (1990) relatou que a água ozonizada manteve sua atividade antimicrobiana até 20 minutos e que essa atividade diminuiu substancialmente após 30 minutos devido à instabilidade do gás $\mathrm{O}_{3}$ e Nagayoshi e colaboradores (2005) confirmou que a atividade antimicrobiana da água ozonizada foi reduzida quando adicionado gota a gota na placa de cultura, ressaltando a rápida degradação como uma das principais desvantagens da água ozonizada, produzindo uma rápida diminuição da atividade microbicida. De acordo com Mandhare e colaboradores (2012), a meia-vida do ozônio varia conforme a temperatura, sendo que a $20^{\circ} \mathrm{C}$, a meia-vida é de 40 minutos a $0^{\circ} \mathrm{C}$, cerca de 140 minutos.

Huth e colaboradores (2008) realizaram experiências dose-resposta para ozônio aquoso e gasoso cobrindo uma faixa de concentração ampla possível para avaliar se havia uma concentração que poderia competir com agentes antimicrobianos já utilizados. Em cultura planctônica o ozônio aquoso completamente eliminou C. albicans quando usado em concentrações 5 $\mu \mathrm{g} / \mathrm{mL}$ enquanto concentrações mais baixas como 2,5 e 1,25 $\mu \mathrm{g} / \mathrm{mL}$ reduziu substancialmente, mas não os eliminou totalmente. O gás de ozônio em concentrações de $1 \mathrm{gm}^{3}$ por $1 \mathrm{~min}$, eliminou quase completamente as cepas testadas com uma redução média de mais de $99 \%$. Além disso, relataram que a eliminação completa dos microrganismos poderia ser obtida na forma gasosa a $32 \mathrm{gm}^{3}$ por 1 minuto ou a uma concentração mais baixa para maior tempo de contato.

Outra característica importante foi de que a água ozonizada não apresenta efeito residual (Cardoso et al., 2008), pois após um período de tempo os microrganismos restantes no modelo estudado voltaram a se multiplicar. Considera-se isso uma desvantagem importante, pois torna o tratamento com ozônio uma opção disponível apenas em clínicas equipadas, não ocorrendo a possibilidade de comercialização da água ozonizada, diferentemente de outros antimicrobianos já utilizados.

Shargawi e colaboradores (1999), expuseram a superfície do ágar ao ozônio, com posterior cultivo e contagem de UFC, concluindo que as contagens viáveis não diferiram entre as placas controle e as placas expostas antes da inoculação, indicando que o gás não exerce efeito sobre a levedura em crescimento, podendo até provocar uma mudança no próprio meio de cultura. Corroborando com esse dado, Arita et al. (2005) analisaram o perfil morfológico de C. albicans anexado a placas de resina, tendo significativa quantidade de cepas observadas, mesmo quando essas placas foram pré-imersas em água ozonizada, obtendo redução apenas no tratamento após a inoculação e o crescimento do fungo.

Baseado nisso, observa-se uma incoerência a respeito dos protocolos para implementação da ozonioterapia, que pode ser explicada devido a uma falta de estudos na área e a dificuldade de se trabalhar com o gás em ambiente clínico, por conta de sua instabilidade. Porém, como estratégia de gerenciamento alternativo, o ozônio continua sendo recomendado devido à sua poderosa capacidade de inativar microrganismos, somado ao fator de haver evidências crescentes de que ele pode ser empregado como um agente terapêutico útil no tratamento odontológico, seja em relação à periodontite associada a bactérias, vírus e fungos (Kshitish \& Laxman, 2010), estomatite protética (Muller et al., 2007), irrigação de canais radiculares (Cardoso et al., 2008), limpeza da cavidade após remoção da biomassa cariogênica (Safwat et al., 2018) ou desinfecção de matérias de uso clinico (Savabi et al., 2018).

\section{Considerações Finais}

Conforme observado o ozônio causa a inativação de inúmeros microrganismos, por meio da ruptura na integridade do envelope celular bacteriano e na quebra da permeabilidade da membrana celular por oxidação de fosfolipídios e lipoproteínas. O ozônio apresenta um significativo efeito sobre leveduras do gênero Candida e levando-se em consideração a complexidade no tratamento da infecção induzida por esse fungo (candidose oral), o presente estudo sugere que a terapia com ozônio tem a possibilidade de atenuar a resposta curativa da infecção por Candida, visto que inúmeros estudos tenham relatado melhora nos quadros infecciosos e diminuição do número de UFC. 
Todavia, novas investigações e comparações de perfil de toxicidade, por meio de ensaios laboratoriais e clínicos, são necessários para estabelecer corretos protocolos de uso.

\section{Referências}

Abaci, O., Haliki-Uztan, A., Ozturk, B., Toksavul, S., Ulusoy, M. \& Boyacioglu, H. (2010). Determining Candida spp. incidence in denture wearers. Mycopathologia, 169(5), 365-372.

Almeida, M. A., Silva, F. A., Guimarães, A. J., Paes, R. A. \& Oliveira, R. M. Z. (2019). The occurrence of histoplasmosis in Brazil: A systematic review. International Journal of Infectious Diseases, 86(1), 147-156.

Amin, L. E. (2018). Biological assessment of ozone therapy on experimental oral candidiasis in immunosuppressed rats. Biochemistry and Biophysics Reports, $15(1), 57-60$

Arita, M., Nagayoshi, M., Fukuizumi, T., Okinaga, T., Masumi, S., Morikawa, M., Kakinoki, Y. \& Nishihara, T. (2005). Microbicidal efficacy of ozonated water against Candida albicans adhering to acrylic denture plates. Oral Microbiology and Imunlogy, 20(4), 206-210.

Bezirtzoglou, E., Cretoui, S. M., Moldoveanu, M., Alexopouos, A., Lazar, V. \& Nakou, M. (2008). A quantitative approach to the effectiveness of ozone against microbiota organisms colonizing toothbrushes. Journal of Dentistry, 36(5), 600-605.

Bocci, V., Zanardi, I. \& Travagli, V. (2011). Ozone acting on human blood yields a hormetic dose-response relationship. Journal of Translation Medicine, $9(1), 2-11$.

Borges, G. A., Elias, S. T., da Silva, S. M. M., Magalhães, P. O., Macedo, S. B., Riberio, A. P. D. \& Guerra, E. L. S. (2017). In vitro evaluation of wound healing and antimicrobial potential of ozone therapy. Journal of Cranio-Maxilo-Facial Surgery, 45(3), 364-370.

Cardoso, M. G., de Oliveira, L. D., Koga-Ito, C. Y. \& Jorge, A. O. C. (2008). Effectiveness of ozonated water on Candida albicans, Enterococcus faecalis, and endotoxins in root canals. Oral surgery, oral medicine, oral pathology and oral radiology, 105(3), 85-91.

César, J., Sumita, T. C., Junqueira, J. C., Jorge, A. O. C. \& Rego, M. A. (2012). Antimicrobial effects of ozonated water on the sanitization of dental instruments contaminated. Journal of Infection and Public Health, 5(1), 269-274.

Dziugan, P., Balcerek, M., Binczarski, M.J., Kreigiel, D. \& Kunicka-Styczynska, A. (2016). Ozonation as an effective way to stabilize new kinds of fermentation media used in biotechnological production of liquid fuel additives. Biotechnology for Biofuels, 9(150), 1-9.

Eick, S., Tigan, M. \& Sculean, A. (2012). Effect of ozone on periodontopathogenic species. Clinical Oral Investigation, 16(2), 537-544.

Farah, C. S., Lynch, N. \& McCullough, M. J. (2010). Oral fungal infections: an update for the general practitioner. Australian Dental Journal, 55(1), 48-54.

Fotos, P. G. \& Hellstein, J. W. (1992). Candida and candidosis: Epidemiology, diagnosis, and therapeutic management. Dental Clinics of North America, $36(4), 857-78$.

Gold, J. A. (2008). The role of chlorhexidine in caries prevention. Operative Dentistry, 33(6), 710-716.

Hahnel, S., Rosentritt, M., Bürgers, R., Handel, G. \& Lang R. (2012). Candida albicans biofilm formation on soft denture liners and efficacy of cleaning protocols. Gerodontology, 29(2), 383-391.

Huth, K. C., Jakob, F. M. \& Saugel, B. (2006) Effect of ozone on oral cells compared with established antimicrobials. European Journal of Oral Science, 114(5), 435-440.

Huth, K. C., Quirling, M., Maier, S., Kamereck, K., Alkhayer, M., Paschos, E., Welsh, U., Miethke, T., Brand, K. \& Hickel, R. (2008). Effectiveness of ozone against endodontopathogenic microorganisms in a root canal biofilm model. International Endodontic Journal, 42(1), 3-13.

Komanapalli, I. R. \& Lau, B. H. S. (1998). Inativation of bacteriophage, Escherichia coli and Candida albicans by ozone. Applied Microbiology and Biotechnology, 49(1), 766-769.

Kshitish, D. \& Laxman, V. D. (2010). The use of ozonated water and $0.2 \%$ chlorhexidine in the treatment of periodontitis patients: A clinical and microbiologic study. Indian Journal of Dental Research, 21(3), 341-348.

Livingston, S., Cadnum, J. L., Gestrich, S., Jencson, A. L. \& Donksey C. J. (2018). Efficacy of automated disinfection with ozonated water in reducing sink drainage system colonization with Pseudomonas species and Candida auris. Infection Control \& Hospital Epidemiology, 39(12), 1497-1498.

Mandhare, M. N., Jagdale, D. M., Gaikwad, P. L., Gandhi, P. S. \& Kadam, V. J. (2012). Miracle of ozone therapy as an alternative medicine. International Journal of Pharmaceutical, Chemical and Biological Sciences, 2(1), 63-71.

Miguez, F., Gómez-Lus, M. L., Andre, J., Cabronero, M. J. \& Pietro, J. (1990). Antimicrobial activity of ozonized water in determined experimental conditions. Revista de Sanidad e Higiene Publica, 64(7), 415-423.

Mu, G., Liu, H., Chen, M., Liu, X. \& Ou, C. (2020). Ozone treatment unveils the veil Candida Parapsilosis infection in the knee joint: a case report and literature review. Mycopathologia, 185(3), 545-554.

Muller, P., Guggenheim, B. \& Schmidlin, P. R. (2007). Efficacy of gasiform ozone and photodynamic therapy on a multispecies oral biofilm in vitro. European Journal of Oral Science, 115(1), 77-80. 
Murakami, H., Sakuma, S., Nakamura, K., Ito, Y., Hattori, M., Asai, A., Noguchi, T. \& Nagao, T. (1996). Desinfection of removable dentures using ozone. Dental Material Journal, 15(2), 220-225.

Nagayoshi, M., Fukuizumi, T., Kitamura, C., Yano, J., Terashita, M. \& Nishihara, T. (2004) Efficacy of ozone on survival and permeability of oral microorganisms. Oral Microbiology and Immunology, 19(4), 240-246.

Nagayoshi, M., Fukuizumi, T., Okinaga, T., Masumi, S., Morikawa, M., Kakinoki, Y. \& Niishihara, T. (2005). Microbicidal efficacy of ozonated water against Candida albicans adhering to acrylic denture plates. Oral Microbiology and Immunology, 20(4), 206-210.

Noites, R., Pina-Vaz, C., Rocha, R., Carvalho, M. F., Gonçalves, A. \& Pina-Vaz, I. (2014). Synergistic antimicrobial action of Chlorhexidine and Ozone in endodontic treatment. BioMed Research International, 10(1), 1-6.

Paster, B. J., Olsen, I., Aas, J. A. \& Dewhirst, F. E. (2006). The breadth of bacterial diversity in the human periodontal pocket and other oral sites. Periodontology 2000, 42(1), 80-87.

Pivotto, A. P., Banhuk, F. W., Staffen, I. V., Daga, M. A., Ayala, T. S. \& Menolli, R. A. (2020). Clinical Uses and Molecular Aspects of Ozone Therapy: A Review. Online Journal of Biological Sciences, 20(1), 37-49.

Quindós, G., Gil-Alonso, S., Marcos-Arias, C., Sevillano, E., Mateo, E., Jauregizar, N. \& Eraso, E. (2019). Therapeutic tools for oral candidiasis: Current and new antifungal drugs. Medicina Oral, Patologia Oral y Cirurgia Bucal, 24(2), 172-180.

Restaino, L., Frampton, E. W., Hemphill, J. B. \& Palnikar, P. (1995). Efficacy of ozonated water against various food-related microorganisms. Applied and Environmental Microbiology, 61(9), 3471-3475.

Sadatullah, S., Mohamed, N. H. \& Razak, F. A. (2012). The antimicrobial effect of 0.1 ppm ozonated water on 24-hour plaque microorganisms in situ. Brazilian Oral Research, 26(2), 126-131.

Safwat, O., Elkateb, M., Dowidar, K., Salam, H. A. \& Meligy, O. (2018). Microbioloical evaluation of ozone on dentinal lesions in young permanent molars using the stepwise excavation. The Jornal of Clinical Pediatric Dentistry, 42(6), 11-20.

Saini, R. (2011). Ozone therapy in dentistry: A strategic review. Journal of Natural Science, Biology and Medicine, 2(2), $151-153$.

Savabi, O., Nejatidanesh, F., Bagheri, K. P., Karimi, L. \& Savabi, G. (2018). Prevention of cross-contamination risk by disinfection of irreversible hydrocolloid impression materials with ozonated water. International Journal of Preventive Medicine, 9(37), 1-5.

Shargawi, J. M., Theaker, E. D., Drucker, D. B., McFarlane, T. \& Duxbury, A. J. (1999). Sensitivity of Candida albicans to negative air ions streams. Journal of Applied Microbiology, 87(6), 889-897.

Sherman, R. G., Prusinski, L., Ravenel, M. C. \& Joralmon, R. A. (2002). Oral Candidoses. Quintessense International, 33(7), $521-532$.

Smith, N. L., Wilson, A. L., Gandhi, J., Vatsia, S. \& Khan, S. (2017). Ozone therapy: An overview of pharmacodynamics, current research and clinical utility. Medical Gas Research, 7(3), 212-219.

Simões, R. J., Fonseca, P. \& Figueiral, M. H. (2018). Oral infections by Candida spp. Scientific Clinical Odontology, 12(1), 19-22.

Tasdemir, Z., Oskaybas, M. N., Alkan, A. B. \& Cakmak O. (2019). The effects of ozone therapy on periodontal therapy: A randomized placebo-controlled clinical trial. Oral Diseases, 25(4), 1195-1202.

Tiwari, S., Avinash, A., Katiyar, S., Iyer, A. A. \& Jain, S. (2017). Dental applications of ozone therapy: A review of literature. The Saudi Journal for Dental Research, 8(2), 105-11.

Tobaldini-Valerio, F. K., Mendonça, P. S. B., Rosseto, H., Bruschi, M., Henriques, M., Negri, M., Silva, S., Svidzinski, T. (2016). Propolis: a potential natural product to figth Candida species infections. Future Microbiology, 11(1) 1035-1046.

Vanden Abbeele, A., de Meel, H., Ahariz, M., Perraudin, J. P., Beyer, I. \& Courtois, P. (2008) Denture contamination by yeasts in the elderly. Gerodontology, 25(4), 222-228

Yamayoshi, T. \& Tatsumi, N. (1993). Microbicidal effect of ozone solution on methicillin-resistant staphylococcus aureus. Drugs under Experimental and Clinical Research, 19(2), 59-64.

Yapar N. Epidemiology and risk factors for invasive candidiasis. (2014). Therapeutics and Clinical Risk Management, 13(10), 95-105. 